\title{
Outcomes of surgical resection for gastric cancer liver metastases: a retrospective analysis
}

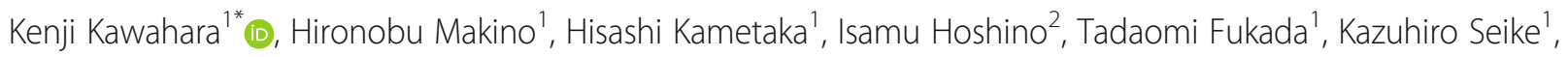
Yohei Kawasaki ${ }^{3}$ and Masayuki Otsuka ${ }^{4}$

\begin{abstract}
Background: The indications for the surgical treatment of gastric cancer liver metastases (GCLMs) remain controversial. In addition, the outcome of surgery for the treatment of liver metastases of alpha-fetoprotein-producing gastric cancer (AFPGC) has not yet been reported. We assessed the clinicopathologic features, including AFP-GC, and the surgical results of these patients.

Methods: This retrospective study analyzed 20 patients who underwent hepatectomy for GCLM at Odawara Municipal Hospital between April 2006 and January 2016.

Results: The actuarial 1-, 3-, and 5-year overall survival (OS) rates after primary hepatectomy were $80.0 \%$, 55.5\%, and 31.7\%, respectively, with a median OS of 42 months. Four patients survived for more than 5 years after their final hepatectomy procedures. A multivariate analysis showed multiple metastases in the liver, the elevated level of carbohydrate antigen 19-9 (CA19-9), and an age of less than 70 years to be independently associated with a poor prognosis in terms of OS. No significant differences were noted between the AFP-GC and AFP-negative GC groups.

Conclusion: Surgical treatment is therefore considered to be a feasible option for GCLM. The findings of the present study showed the number of metastatic liver tumors, the level of CA19-9, and the patient age to be prognostic indicators for the surgical treatment of GCLM.
\end{abstract}

Keywords: Gastric cancer, Liver metastases, Hepatectomy, Alpha-fetoprotein-producing gastric cancer, Metastasis

\section{Introduction}

Gastric cancer is one of the most common malignant tumors and the fourth leading cause of cancer-related death worldwide. Recently, the treatment of gastric cancer has improved drastically. The role of resection for colorectal cancer liver metastases has been well established. However, the indication of surgical treatment for gastric cancer liver metastases (GCLMs) remains controversial [1]. The liver is a frequent site of distant metastasis from gastric cancer, with an incidence of 5-34\% [2, 3]. However, the most common site of metastatic recurrence of gastric cancer is the peritoneum, with an incidence of $45-50 \%[2,4]$. Several retrospective studies concerning the surgical

\footnotetext{
* Correspondence: axha4717@chiba-u.jp

'Department of Surgery, Odawara Municipal Hospital, 46 Kuno, Odawara City, Kanagawa Prefecture, Japan

Full list of author information is available at the end of the article
}

treatment of GCLM have reported favorable results. In the present study, we assessed the clinicopathologic features and surgical outcomes of patients with GCLM.

Alpha-fetoprotein (AFP) was initially found in the human fetus and is normally produced in the fetal liver and yolk sac. An elevated serum AFP level is usually associated with hepatocellular carcinoma, yolk sac tumor, cirrhosis, and hepatitis. AFP-producing tumors originate in several organs, including the gastrointestinal tract, lung, kidney, and ovary. Gastric cancer is one of the most common cancers, and its AFP-positive variant has been reported to be characterized by a high proliferative activity, weak apoptosis, and rich neovascularization in comparison to AFPnegative gastric cancers [5]. Although AFP-producing gastric cancer (AFP-GC) is a rare subtype of gastric cancer, it is associated with a high incidence of liver metastasis and 
a poor prognosis. We therefore also analyzed the surgical outcomes of AFP-GC liver metastases.

\section{Methods}

\section{Patient population and data collection}

Between April 2006 and January 2016, 20 patients with GCLM were treated surgically at Odawara Municipal Hospital. All eligible patients met the following criteria: (i) no signs of extrahepatic metastasis; (ii) an acceptable hepatic functional reserve, as assessed by the indocyanine green clearance rate and Child-Pugh score; (iii) intention to perform curative gastrectomy; and (iv) macroscopic complete resection. The number, size, and location of the liver tumors were not considered. The decision to administer chemotherapy after hepatectomy was left to each surgeon. The regional tumor and node categories and histological type were classified according to the Japanese Classification of Gastric Carcinoma [6].

\section{Classification of AFP-positive gastric cancer}

We defined AFP-GC as follows: a high preoperative serum AFP level $(\geq 10 \mu \mathrm{g} / \mathrm{L})$ that decreased after surgery or positive immunohistochemical staining of AFP in the primary lesion, regardless of the serum AFP level. A monoclonal antibody (clone ZSA06, prediluted, Nichirei) was used, and antigen retrieval was not required. Immunohistochemical staining of AFP in liver metastasis was not considered.

\section{Statistical analyses}

The statistical significance of differences was determined using a log-rank test. A multivariate analysis was performed using a Cox proportional hazards model. Confounding variables for the overall survival (OS) were identified using stepwise multivariate logistic regression analysis. Baseline variables with $P$ values of $<0.05$ in the univariate analysis were included in the multivariate models, and the number of liver metastases that was the most frequent independent prognostic factor in other studies was included as independent variables via the forced entry method. The stepwise multivariate logistic regression using Bayesian information criterion (BIC) selection method was used to select the prognostic factors for inclusion as independent variables [7]. Survival curves were generated using the Kaplan-Meier method. The OS and relapse-free survival (RFS) times were measured from the date of primary hepatic resection. All statistical analyses were performed using JMP $^{\circ} 13$ (SAS Institute Inc., Cary, NC, USA).

In reports with the gastrectomy of the National Clinical Database of Japan, the average age of patients with distal gastrectomy was 70 years old (Standard deviation; 11.8 ), and the average age of patients with total gastrectomy was 68.9 years old $[8,9]$. In this study, the mean age of patients was 71.5 years, but the cutoff value was 70 years old because there were no patients between 68 and 72 years old.

\section{Results}

\section{Patient characteristics}

The clinicopathological characteristics of the 20 patients are presented in Table 1. Eleven patients were treated with gastrectomy and hepatectomy for synchronous liver metastases, while the other nine underwent hepatectomy for the recurrence of gastric cancer in the liver. The median interval between gastrectomy and hepatectomy for metachronous liver metastases was 10 months (range, 440 months). Five patients underwent repeat hepatectomy (one patient received surgery twice). No postoperative complications were seen in any patients. Four patients survived for 5 years without recurrence after their latest hepatectomy procedure.

\section{Outcomes of surgery for AFP-GC liver metastasis}

The serum AFP level was analyzed in 15 patients. Three of these 15 patients had elevated serum AFP levels that decreased after surgery (preoperative AFP/postoperative AFP $[\mu \mathrm{g} / \mathrm{L}]$ 46.1/4.8, 458.2/4.2, 21160.0/624.0). Another had an elevated serum AFP level that did not change after surgery $(20.1 / 20.6 \mu \mathrm{g} / \mathrm{L})$. We also performed immunohistochemical staining of AFP in all primary lesions. In one patient, the serum AFP level was high, and immunohistochemical staining of AFP was also findings for. Another patient in whom we did not measure the serum AFP level, immunohistochemical staining of AFP showed focal positivity, and we defined this as a case of AFP-GC. Four patients were classified into the AFP-GC group (Fig. 1). No significant differences were noted between the AFP-GC and AFP-negative GC groups (hazard ratio $[\mathrm{HR}] 1.66,95 \%$ confidence interval $[\mathrm{CI}] 0.36-$ $5.78, p=0.453)$.

\section{Long-term outcomes}

The median length of follow-up was 77 months (95\% CI 19-117) (Kaplan-Meier estimate). The actuarial 1-, 3-, and 5-year OS rates after first hepatectomy were $80.0 \%$, $55.5 \%$, and $31.7 \%$, respectively, with a median OS of 42 months. The actuarial 1-, 3-, and 5-year RFS rates were $35.0 \%, 24.0 \%$, and $18.0 \%$, respectively, with a median RFS of 10.5 months (Fig. 2). There were no cases of postoperative mortality.

\section{Prognostic factors}

In the univariate analysis, significant differences were observed between the GC groups in the age $(p=0.004)$, size of the primary tumor $(p=0.041)$, type of gastrectomy $(p=0.009)$, and preoperative level of carbohydrate antigen (CA) 19-9 ( $p=0.003)$ (Table 2). No significant 
Table 1 Clinicopathological characteristics

\begin{tabular}{|c|c|}
\hline Variables & \\
\hline \multicolumn{2}{|l|}{ Sex } \\
\hline Male & 13 \\
\hline Female & 7 \\
\hline Age (years)* & $73.5(53-89)$ \\
\hline \multicolumn{2}{|l|}{ Histological type } \\
\hline Well & 3 \\
\hline Mod & 11 \\
\hline Poor & 3 \\
\hline Muc & 3 \\
\hline Size of primary tumor $(\mathrm{cm})^{*}$ & $4.5(2.0-9.0)$ \\
\hline \multicolumn{2}{|l|}{ Type of gastrectomy } \\
\hline Total gastrectomy & 8 \\
\hline Distal gastrectomy & 11 \\
\hline Proximal gastrectomy & 1 \\
\hline \multicolumn{2}{|l|}{ Serosal invasion } \\
\hline Present & 4 \\
\hline Absent & 16 \\
\hline \multicolumn{2}{|l|}{ Lymph node metastasis } \\
\hline NO & 3 \\
\hline N1 $(1,2)$ & 5 \\
\hline N2 (3-6) & 8 \\
\hline N3 $(7 \leq)$ & 4 \\
\hline \multicolumn{2}{|l|}{ Lymphatic invasion } \\
\hline ly0 & 6 \\
\hline ly1 & 6 \\
\hline ly2 & 5 \\
\hline ly3 & 3 \\
\hline \multicolumn{2}{|l|}{ Venous invasion } \\
\hline vo & 7 \\
\hline v1 & 3 \\
\hline v2 & 6 \\
\hline v3 & 4 \\
\hline Number of hepatic tumors* & $1.0(1-22)$ \\
\hline Maximum size of the metastatic tumor $(\mathrm{cm})^{*}$ & $2.5(0.8-7.5)$ \\
\hline \multicolumn{2}{|l|}{ Time of hepatectomy } \\
\hline Synchronous & 11 \\
\hline Metachronous & 9 \\
\hline \multicolumn{2}{|l|}{ Repeat hepatectomy } \\
\hline Once & 15 \\
\hline Repeat & 5 \\
\hline Postoperative chemotherapy (cycle)* & $4.0(0-27)$ \\
\hline CEA $(n g / m L) *$ & $3.5(0.8-2230)$ \\
\hline CA19-9 $(\mathrm{U} / \mathrm{mL})^{*}$ & $13.3(0.1-236.2)$ \\
\hline
\end{tabular}

Table 1 Clinicopathological characteristics (Continued)

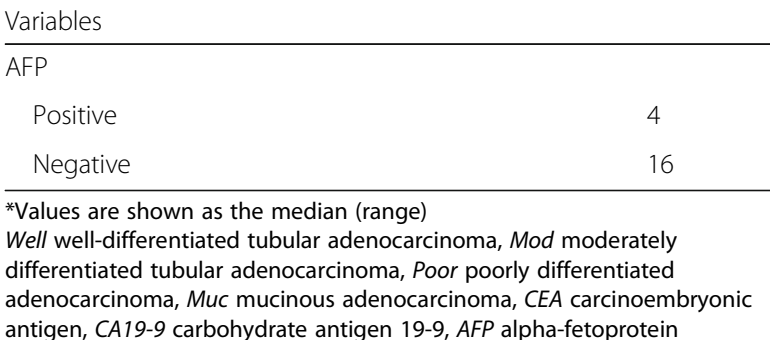

difference was observed in the survival between 11 patients synchronous GCLMs and 9 patients with metachronous liver metastases $(p=0.660)$. In addition, not only between the AFP-GC and AFP-negative GC groups, but also between differentiated adenocarcinoma and undifferentiated adenocarcinoma groups; no significant difference was observed. A multivariate analysis showed that multiple metastasis in the liver, the elevated level of carbohydrate antigen 19-9 (CA19-9), and age under 70 years were independently associated with a poor prognosis in terms of OS (Table 3).

\section{Discussion}

The incidence of synchronous GCLM is reported to be $2.2-14 \%$ [3, 10-15]. However, after curative resection of primary gastric cancer, $1.5-13.5 \%$ of patients experience intrahepatic recurrence [3, 11-13, 16, 17]. Furthermore, the incidence of AFP-GC has been reported to be 1.8 $6.6 \%$ [18-22], and liver metastasis occurs in 43.5-60.5\% of patients with AFP-GC [19-22]. Consequently, at least $5.6 \%$ of GCLM is estimated to be AFP-GC, and AFPproducing GCLM may be considered an important prognostic factor for resection. However, no study on the surgical treatment of liver metastasis from gastric cancer have mentioned of AFP-GC. In the present study, which included 4 patients (20\%) with AFP-GC, the overall survival of patients with AFP-GC and AFP-negative gastric cancer did not differ to a statistically significant extent. Accordingly, studies on the surgical treatment of liver metastasis from gastric cancer may have unexpectedly included many AFP-GC patients. AFP-GC may not be a poor prognostic factor for patients undergoing hepatectomy for liver metastases from gastric cancer or this may be false negative due to insufficient power of this study. Incidentally, no cases of hepatoid adenocarcinoma were included in the present study. Hepatoid adenocarcinoma is a very rare extrahepatic tumor characterized by a hepatocellular carcinoma-like histology and often produces AFP [23]. This occurs in several organs, including the lungs, gallbladder, esophagus, and uterus, and arises most frequently in the stomach, which accounts for $63 \%$ of cases [24]. Gastric hepatoid adenocarcinoma is considered a more aggressive tumor than AFP-GC [21]. 


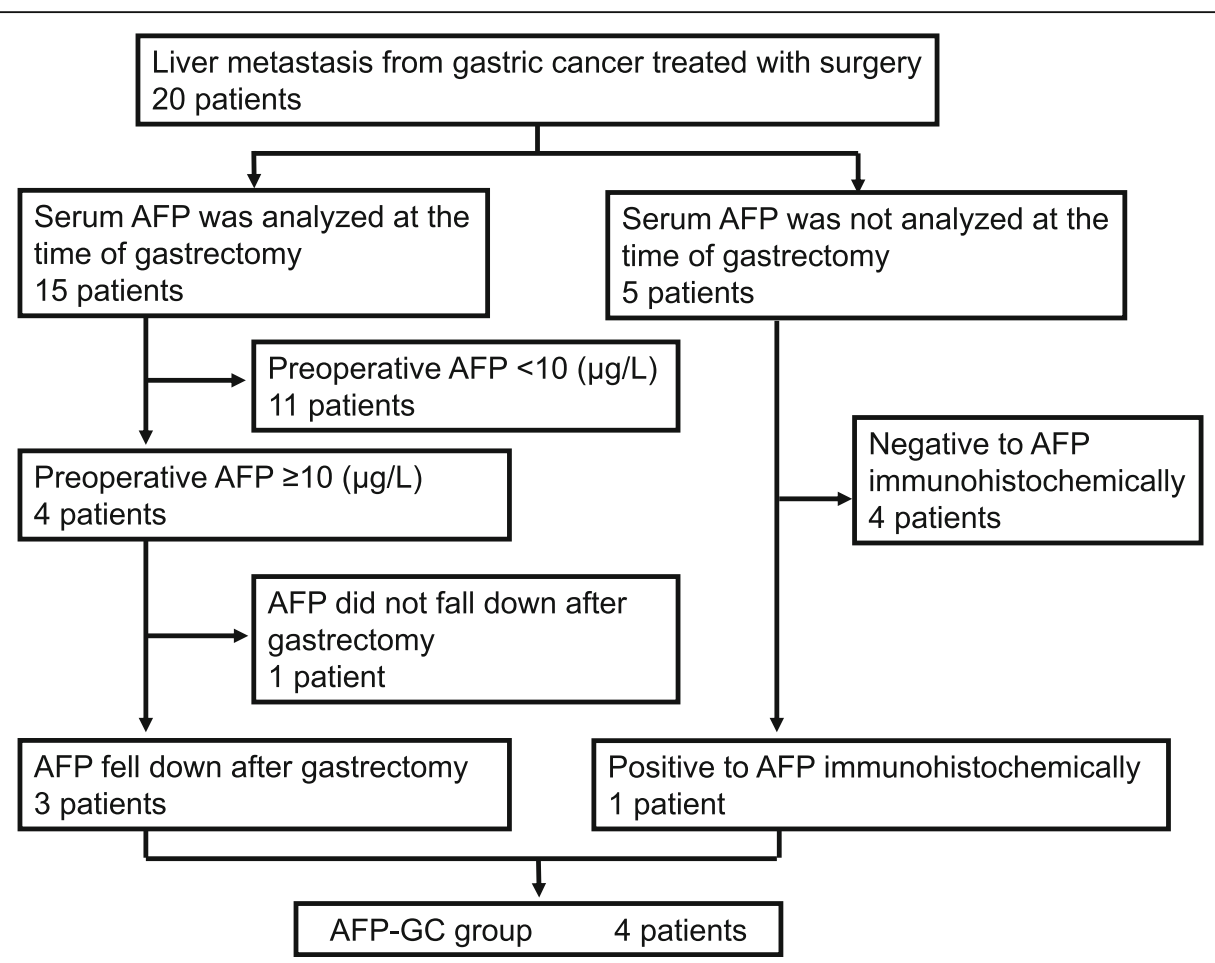

Fig. 1 Flow chart of the selection of AFP-GC patients

The present study showed that the age, level of CA19-9, and number of liver metastases were independent prognostic factors. However, few studies have reported that the prognosis of gastric cancer in younger patients is poorer than that in older patients. Although not statistically significant, patients older than 70 years tended to have fewer liver metastases $(p=0.139$ (Mann-Whitney $U$ test)), smaller size of largest liver metastases $(p=0.140$ (Mann-Whitney $U$ test)), smaller size of the primary tumor ( $p=0.255$ (Mann-Whitney $U$ test)), and less serosal

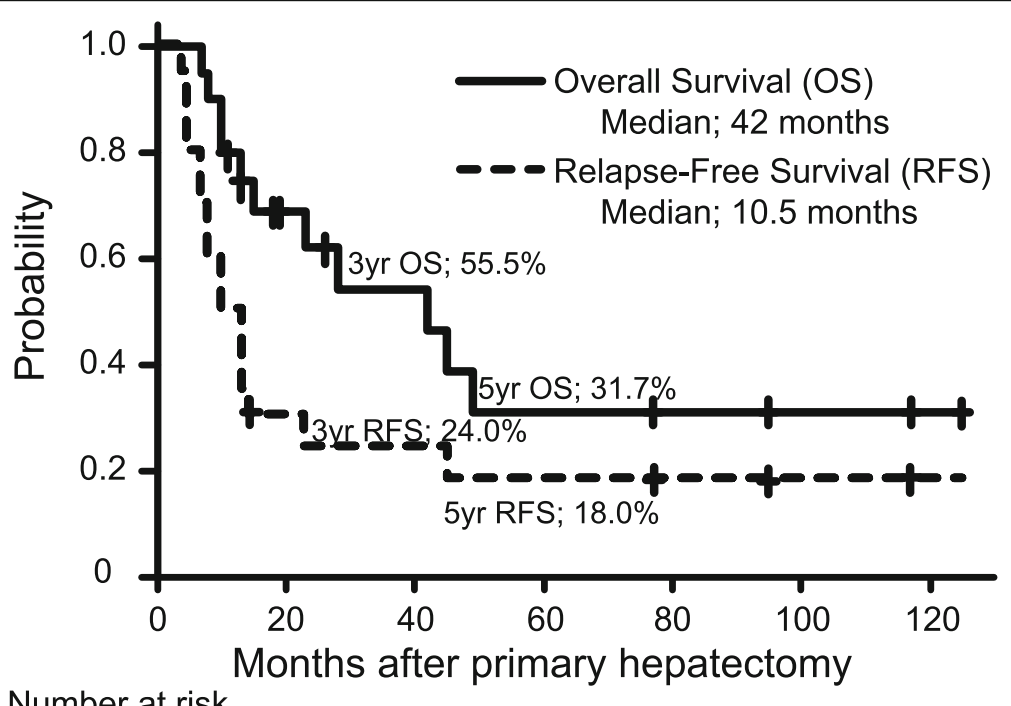

Number at risk

$\begin{array}{cccccccc}\text { OS } & 20 & 11 & 7 & 4 & 3 & 2 & 1 \\ \text { RFS } & 20 & 5 & 4 & 3 & 2 & 1 & 0\end{array}$

Fig. 2 A Kaplan-Meier analysis of overall and relapse-free survival 
Table 2 Results of a univariate analysis of the overall survival according to the clinicopathological factors

\begin{tabular}{|c|c|c|c|c|c|}
\hline Characteristics & & $n$ & $H R$ & $95 \% \mathrm{Cl}$ & $p$ value* \\
\hline \multirow[t]{2}{*}{ Sex } & Male & 13 & 0.64 & $0.19-2.24$ & 0.459 \\
\hline & Female & 7 & 1 & & \\
\hline \multirow[t]{2}{*}{ Age (years) } & $>70$ & 13 & 0.20 & $0.05-0.67$ & 0.004 \\
\hline & $<70$ & 7 & 1 & & \\
\hline \multirow[t]{2}{*}{ Histological type } & Well/mod & 14 & 2.10 & $0.54-13.77$ & 0.331 \\
\hline & Poor/muc & 6 & 1 & & \\
\hline \multirow[t]{2}{*}{ Size of primary tumor $(\mathrm{cm})$} & $\geq 5$ & 10 & 4.10 & $1.02-20.4$ & 0.041 \\
\hline & $<5$ & 10 & 1 & & \\
\hline \multirow[t]{2}{*}{ Type of gastrectomy (partial; distal 11, proximal 1) } & Total gastrectomy & 8 & 5.60 & $1.40-27.82$ & 0.009 \\
\hline & Partial gastrectomy & 12 & 1 & & \\
\hline \multirow[t]{2}{*}{ Serosal invasion } & Present & 4 & 1.17 & $0.17-4.89$ & 0.841 \\
\hline & Absent & 16 & 1 & & \\
\hline \multirow[t]{2}{*}{ Lymph node metastasis } & N2/N3 & 12 & 1.68 & $0.50-6.53$ & 0.406 \\
\hline & No/N1 & 8 & 1 & & \\
\hline \multirow[t]{2}{*}{ Lymphatic invasion } & ly2/ly3 & 11 & 0.39 & $0.08-1.35$ & 0.150 \\
\hline & ly0/ly1 & 9 & 1 & & \\
\hline \multirow[t]{2}{*}{ Venous invasion } & $\mathrm{v} 2 / \mathrm{v} 3$ & 11 & 0.57 & $0.16-1.92$ & 0.354 \\
\hline & $\mathrm{v} 0 / \mathrm{v} 1$ & 9 & 1 & & \\
\hline \multirow[t]{2}{*}{ Number of hepatic tumors } & Solitary & 11 & 0.34 & $0.08-116$ & 0.077 \\
\hline & Multiple & 9 & 1 & & \\
\hline \multirow[t]{2}{*}{ Maximum size of the metastatic tumor } & $\leq 3 \mathrm{~cm}$ & 14 & 0.41 & $0.12-1.40$ & 0.197 \\
\hline & $>3 \mathrm{~cm}$ & 6 & 1 & & \\
\hline \multirow[t]{2}{*}{ Time of hepatectomy } & Synchronous & 11 & 1.31 & $0.39-4.59$ & 0.660 \\
\hline & Metachronous $^{\ddagger}$ & 9 & 1 & & \\
\hline \multirow[t]{2}{*}{ Repeat hepatectomy } & Repeat & 5 & 0.81 & $0.17-2.87$ & 0.758 \\
\hline & Once & 15 & 1 & & \\
\hline \multirow[t]{2}{*}{ Postoperative chemotherapy (cycle) } & $\geq 3$ & 11 & 0.47 & $0.13-1.57$ & 0.203 \\
\hline & $<3$ & 9 & 1 & & \\
\hline \multirow[t]{2}{*}{ CEA (ng/mL) } & $\geq 6.0$ & 6 & 5.57 & $1.34-27.79$ & 0.091 \\
\hline & $<6.0$ & 14 & 1 & & \\
\hline \multirow[t]{2}{*}{ CA19-9 (U/mL) } & $\geq 37.0$ & 4 & 7.94 & $1.42-44.33$ & 0.003 \\
\hline & $<37.0$ & 16 & 1 & & \\
\hline \multirow[t]{2}{*}{ AFP } & Positive & 4 & 1.66 & $0.36-5.78$ & 0.453 \\
\hline & Negative & 16 & 1 & & \\
\hline
\end{tabular}

HR hazard ratio, $\mathrm{Cl}$ confidence interval, Inf infinity, Well well-differentiated tubular adenocarcinoma, Mod moderately differentiated tubular adenocarcinoma, Poor poorly differentiated adenocarcinoma, Muc mucinous adenocarcinoma, CEA carcinoembryonic antigen, CA19-9 carbohydrate antigen 19-9, AFP alpha-fetoprotein *Log-rank test

FThe median interval between gastrectomy and primary hepatectomy was 18.0 months (range 4-42)

Table 3 Results of a multivariate analysis of predictive factors

\begin{tabular}{lllll}
\hline Characteristics & & $\mathrm{HR}$ & $95 \% \mathrm{Cl}$ & $p$ value \\
\hline Age (years) & $>70$ & 0.071 & $0.01-0.40$ & 0.003 \\
CA19-9 $(\mathrm{U} / \mathrm{mL})$ & $\geq 37.0$ & 22.35 & $2.68-186.6$ & 0.004 \\
Number of liver metastases & Solitary & 0.165 & $0.03-0.91$ & 0.038
\end{tabular}

$H R$ hazard ratio, $\mathrm{Cl}$ confidence interval invasion $(p=0.587$ (Fisher's test)). These may have contributed to the favorable prognosis of elderly patients and this may be type II statistical error due to the sample size limitation.

Several studies have described significant prognostic factors (Table 4). Ten of 17 studies, including more than 20 patients, reported the number of liver metastases as 
Table 4 Reported series of surgical resection for gastric cancer liver metastases including more than 20 patients

\begin{tabular}{|c|c|c|c|c|c|c|c|c|c|c|}
\hline \multirow[t]{2}{*}{ Author } & \multirow[t]{2}{*}{ Year } & \multirow[t]{2}{*}{ Institution } & \multirow[t]{2}{*}{$n$} & \multicolumn{3}{|c|}{ Survival rate (\%) } & \multirow{2}{*}{ MST } & \multirow[t]{2}{*}{ Favorable prognostic factors } & \multicolumn{2}{|c|}{ Period } \\
\hline & & & & $\begin{array}{l}1 \\
\text { year }\end{array}$ & $\begin{array}{l}3 \\
\text { years }\end{array}$ & $\begin{array}{l}5 \\
\text { years }\end{array}$ & & & from & to \\
\hline $\begin{array}{l}\text { Ochiai et al. } \\
\text { [25] }\end{array}$ & 1994 & $\begin{array}{l}\text { National Cancer Center } \\
\text { Hospital, Japan }\end{array}$ & 21 & & & 0.2 & 18 & $\begin{array}{l}\text { Absence of serosal invasion of primary tumor }(T \leq 3) \\
\text { Absence of venous invasion of primary tumor }\end{array}$ & 1962 & 1991 \\
\hline $\begin{array}{l}\text { Miyazaki } \\
\text { et al. [26] }\end{array}$ & 1997 & Chiba Univ., Japan & 21 & & & & & Solitary, surgical margin $\geq 10 \mathrm{~mm}$ & & \\
\hline Ambiru [27] & 2001 & Chiba Univ., Japan & 40 & & & 18 & 12 & Metachronous & 1975 & 1999 \\
\hline $\begin{array}{l}\text { Okano et al. } \\
{[11]}\end{array}$ & 2002 & $\begin{array}{l}\text { Kagawa Med. Univ., } \\
\text { Japan }\end{array}$ & 21 & 77 & 34 & 34 & & $\begin{array}{l}\text { Solitary, metachronous, presence of a pseudocapsule } \\
\text { Well-differentiated adenocarcinoma }\end{array}$ & & \\
\hline $\begin{array}{l}\text { Sakamoto } \\
\text { et al. [3] }\end{array}$ & 2003 & $\begin{array}{l}\text { Cancer Institute } \\
\text { Hospital, Japan }\end{array}$ & 22 & 73 & 38 & 38 & 21.4 & Solitary & 1985 & 2001 \\
\hline $\begin{array}{l}\text { Shirabe et al. } \\
\text { [28] }\end{array}$ & 2003 & Kyusyu Univ., Japan & 36 & 64 & 43 & 26 & & Solitary, absence of venous invasion of primary tumor & & \\
\hline $\begin{array}{l}\text { Koga et al. } \\
{[12]}\end{array}$ & 2007 & $\begin{array}{l}\text { Cancer Institute } \\
\text { Hospital, Japan }\end{array}$ & 42 & 76 & 48 & 42 & 34 & $\begin{array}{l}\text { Absence of serosal invasion of primary tumor }(T \leq 3) \text {, } \\
\text { solitary }\end{array}$ & 1985 & 2005 \\
\hline $\begin{array}{l}\text { Sakamoto } \\
\text { et al. [13] }\end{array}$ & 2007 & $\begin{array}{l}\text { National Cancer Center } \\
\text { Hospital, Japan }\end{array}$ & 37 & & & 11 & 31 & Unilobar, size of largest hepatic tumor $\leq 4 \mathrm{~cm}$ & 1990 & 2005 \\
\hline $\begin{array}{l}\text { Thelen et al. } \\
\text { [29] }\end{array}$ & 2008 & $\begin{array}{l}\text { Campus Virchow- } \\
\text { Klinikum, Charité Univ., } \\
\text { Germany }\end{array}$ & 24 & 38 & 16 & 10 & 9 & R0 resection & 1988 & 2004 \\
\hline $\begin{array}{l}\text { Cheon et al. } \\
\text { [14] }\end{array}$ & 2008 & Yonsei Univ., Korea & 41 & 75.3 & 31.7 & 20.8 & 17.9 & Solitary & 1995 & 2005 \\
\hline $\begin{array}{l}\text { Takemura } \\
\text { et al. [30] }\end{array}$ & 2012 & $\begin{array}{l}\text { Cancer Institute } \\
\text { Hospital, Japan }\end{array}$ & 64 & 84 & 50 & 37 & 34.0 & $\begin{array}{l}\text { Serosal invasion of primary tumor }(T \leq 3) \\
\text { Size of largest hepatic tumor }<5.0 \mathrm{~cm}\end{array}$ & 1993 & 2011 \\
\hline $\begin{array}{l}\text { Schildberg } \\
\text { et al. [31] }\end{array}$ & 2012 & $\begin{array}{l}\text { Univ. of Erlangen/ } \\
\text { Nürnberg, Germany }\end{array}$ & 31 & & & 13 & & Metachronous, solitary, R0 resection & 1972 & 2008 \\
\hline $\begin{array}{l}\text { Qiu et al. } \\
\text { [15] }\end{array}$ & 2013 & $\begin{array}{l}\text { Sun Yat-Sen Univ., } \\
\text { China }\end{array}$ & 25 & 96.0 & 70.4 & 29.4 & 38.0 & Solitary & 1998 & 2009 \\
\hline $\begin{array}{l}\text { Kinoshita } \\
\text { et al. [32] }\end{array}$ & 2015 & Multicenter in Japan & 256 & 77.3 & 41.9 & 31.1 & 31.1 & $\begin{array}{l}\text { Absence of serosal invasion of primary tumor }(T \leq 3) \text {, } \\
\text { number of liver metastases }<3 \text {, size of largest hepatic } \\
\text { tumor }<5.0 \mathrm{~cm}\end{array}$ & 1990 & 2010 \\
\hline Oki et al. [33] & 2015 & Multicenter in Japan & 94 & & 51.4 & 42.3 & 40.8 & Solitary, low-grade lymph node metastasis ( $\mathrm{N} 0$ or $\mathrm{N} 1$ ) & 2000 & 2010 \\
\hline $\begin{array}{l}\text { Oguro et al. } \\
\text { [34] }\end{array}$ & 2016 & Juntendo Univ., Japan & 26 & 71.3 & 41.8 & 13.9 & 20.1 & Histology (well or mod), metachronous & 2002 & 2012 \\
\hline $\begin{array}{l}\text { Tatsubayashi } \\
\text { et al. [35] }\end{array}$ & 2017 & $\begin{array}{l}\text { Shizuoka Cancer } \\
\text { Center Hospital, Japan }\end{array}$ & 28 & & & 32 & 49 & N/A & 2004 & 2014 \\
\hline Present study & & & 20 & 80.0 & 555 & 31.7 & 42 & Solitary, age $>70$ years, elevated CA19-9 & 2006 & 2016 \\
\hline
\end{tabular}

MST median survival time in months, Well well-differentiated tubular adenocarcinoma, Mod moderately differentiated tubular adenocarcinoma

an independent prognostic factor $[3,11,12,14,15,26$, $28,30-33$. The number of liver metastases may be the most important factor for determining the feasibility of surgical resection. In contrast, the next most frequent independent prognostic factor was absence of serosal invasion of primary tumor, however, only four studies reported on this factor [12, 30, 32, 34].

As for gastric cancer itself, it has been reported that the elevated level of serum CA19-9 may be associated with poor prognosis [36]. However, few studies reported the association between hepatectomy for liver metastases from gastric cancer and CA19-9. Kinoshita et al. reported that elevated level of CA19-9 was associated with poor prognosis in univariate analysis, but not in multivariate analysis [32]. And Qiu et al. reported that CA19-9 was not associated with prognosis [15]. However, given the importance of CA19-9 in gastric cancer, it may also be important in hepatectomy from gastric cancer, and if analyzed in other studies, it may be a prognostic factor.

Regarding the histopathological features of the primary tumor, two out of four patients who survived for more than 5 years after the last hepatectomy were diagnosed with mucinous and poorly differentiated adenocarcinoma (one each). Only Okano et al. and Oguro et al. suggested that the histopathological features of the primary gastric cancer may be a prognostic factor [11,34]. No other studies noted a significant difference in the histopathological 
features between the differentiated and undifferentiated types. Thus, surgeons may not need to hesitate in performing hepatectomy for undifferentiated GCLM or GCLM with other aggressive histopathologic characteristics, providing that extrahepatic tumor dissemination has been ruled out.

Although repeat hepatectomy for liver metastasis due to colorectal cancer has been reported to be associated with a favorable prognosis, this association is controversial in GCLM. Kinoshita et al. reported intrahepatic recurrence in $72 \%$ of cases after primary hepatectomy for GCLM [33]. Takemura et al. reported that intrahepatic recurrence developed in $67.2 \%$ (43 patients) of 64 cases treated with primary curative hepatectomy for GCLM and intrahepatic recurrence with no other site was 34 cases, and 3 of 14 patients treated with repeat hepatectomy survived for more than 5 years [37]. Tatsubayashi et al. observed the long-term survival of two of three patients treated with repeat hepatectomy [35]. However, in the present study, among the 15 patients with recurrence after primary hepatectomy, intrahepatic recurrence was noted in $73 \%$ (11 patients), and intrahepatic recurrence with no other site was noted in $67 \%$ (9 patients). Five patients underwent repeat hepatectomy (one patient underwent surgery twice), and one of them survived for more than 5 years after the last hepatectomy procedure, suggesting that repeat hepatectomy may prolong the survival of patients who develop recurrence in the remnant liver. However, this is a limited situation, and Takemura et al. described that this limited situation represents "natural" selection for patients with tumors exhibiting "better" oncologic behavior, considering the aggressive nature of gastric cancer, which is often associated with the development of extrahepatic metastasis and bilobular multiple intrahepatic recurrence.

Several limitations associated with the present study warrant mention. First, it was based on a retrospective analysis of a small sample size from a single institution without a control group. Second, our study included some patients with a short follow-up period. Although the number of patients included in the present study was small, all of the patients with GCLM who met the previous surgical criteria underwent surgery during the study period. Third, various chemotherapy regimens were used, due to the long investigation period. Ten patients received S-1, nine patients received taxanes, seven patients received irinotecan, five patients received cisplatin, and five patients did not receive adjuvant chemotherapy. Doublet chemotherapy regimens were commonly used. Recent progress in chemotherapy might be the key to further improving the prognosis. Taken together, these findings suggest that multidisciplinary therapy is essential for curing GCLM. Sun Z et al. reported, in the study including 3507 GDLM patients, that the
MST was 8.0 months among synchronous GCLM patients treated with chemotherapy only while the MST was 12.0 months among synchronous GCLM patients treated with radical gastrectomy in continuity with resection of other organs, although no statistical difference was mentioned [38]. It is difficult to compare the effects of hepatectomy and chemotherapy and hepatectomy retrospectively because gastric cancer, which has only hepatic metastases that allow liver resection anatomically and functionally, is a special situation. Therefore, a randomized clinical study should be performed to elucidate the benefit of surgery in patients with resectable GCML in comparison to chemotherapy.

\section{Conclusion}

The present study supports the suggestion of the Japanese gastric cancer treatment guidelines that a multidisciplinary approach including surgery with curative intent may be proposed when the number of metastatic nodules is small, and provided no other non-curative factors are present. Although the present study suggested that elderly patients might benefit from this approach and that the patients with undifferentiated histologic type or AFP-GC may achieve an equal benefit to those with differentiated type or AFP-negative gastric cancer, these notions differ from generally accepted ideas. Furthermore, strict selection criteria should be established to identify patients with GCLM who may benefit from surgical resection.

\section{Abbreviations \\ AFP: Alpha-fetoprotein; AFP-GC: Alpha-fetoprotein-producing gastric cancer; CA19-9: Carbohydrate antigen 19-9; Cl: Confidence interval; GCLM: Gastric cancer liver metastasis; HR: Hazard ratio; MST: Median survival time; OS: Overall survival; RFS: Relapse-free survival}

\section{Acknowledgements \\ Not applicable}

\section{Authors' contributions}

KK wrote the paper. $\mathrm{KK}, \mathrm{HM}, \mathrm{HK}$, and $\mathrm{H}$ collected the date and the literature for the review. KK, HM, and HK analyzed the collected date for patients. HM, $H K, T F$, and KS performed the operations. $\mathrm{H}$ and $\mathrm{MO}$ revised the manuscript for important intellectual content and technical details. YK confirmed the analytical model statistically. All authors have read and approved the final manuscript. We confirm that all of us have met the criteria for authorship as established by the ICMJE.

\section{Funding}

The authors declare they have no funding.

\section{Availability of data and materials}

The anonymized data used and/or analyzed during the current study are available from the corresponding author on reasonable request.

\section{Ethics approval and consent to participate}

This study was approved by the Ethics Committee of the Odawara municipal hospital (Approval No. Byorini1). Informed consent for the surgical procedures was obtained from each patient.

Consent for publication

Not applicable

Competing interests 
The authors declare that they have no competing interests.

\section{Author details}

'Department of Surgery, Odawara Municipal Hospital, 46 Kuno, Odawara City, Kanagawa Prefecture, Japan. ${ }^{2}$ Department of General Surgery, Chiba Cancer Center, 666-2, Nitona-cho, Chuo-ku, Chiba City, Chiba Prefecture, Japan. ${ }^{3}$ Biostatistics Section, Clinical Research Center, Chiba University Hospital, 1-8-1, Inohana, Chuo-ku, Chiba City, Chiba Prefecture, Japan. ${ }^{4}$ Department $f$ General Surgery, Graduate School of Medicine, Chiba University, 1-8-1, Inohana, Chuo-ku, Chiba City, Chiba Prefecture, Japan.

\section{Received: 5 December 2019 Accepted: 13 February 2020} Published online: 24 February 2020

\section{References}

1. Japanese Gastric Cancer Association. Japanese gastric cancer treatment guidelines 2014 (ver. 4). Gastric Cancer. 2017;20:1-19.

2. Ohno S, Fujii T, Ueda S, Nakamoto T, Kinugasa S, Yoshimura H, et al. Predictive factors and timing for liver recurrence after curative resection of gastric carcinoma. Am J Surg. 2003;85:258-63.

3. Sakamoto Y, Ohyama S, Yamamoto J, Yamada K, Seki M, Ohta K, et al. Surgical resection of liver metastases of gastric cancer: an analysis of a 17year experience with 22 patients. Surgery. 2002;133:507-11.

4. Yoo CH, Noh SH, Shin DW, Choi SH, Min JS. Recurrence following curative resection for gastric carcinoma. Br J Surg. 2000;87:236-42.

5. Koide N, Nishio A, Igarashi J, Kajikawa S, Adachi W, Amano J. Alphafetoprotein-producing gastric cancer: histochemical analysis of cell proliferation, apoptosis, and angiogenesis. Am J Gastroenterol. 1999;94: 1658-63.

6. Japanese Gastric Cancer Association. Japanese classification of gastric carcinoma: 3rd English edition. Gastric Cancer. 2011;14:101-12.

7. Schwarz G. Estimating the dimension of a model. Ann Statist. 1978;6:461-4.

8. Kurita N, Miyata H, Gotoh M, Shimada M, Imura S, Kimura W, et al. Risk model for distal gastrectomy when treating gastric cancer on the basis of data from 33,917 Japanese patients collected using a nationwide webbased data entry system. Ann Surg. 2015;262:295-303.

9. Watanabe M, Miyata H, Gotoh M, Baba H, Kimura W, Tomita N, et al. Total gastrectomy risk model: data from 20,011 Japanese patients in a nationwide internet-based database. Ann Surg. 2014;260:1034-9.

10. Zacherl J, Zacherl M, Scheuba C, Steininger R, Wenzl E, Mühlbacher F, et al. Analysis of hepatic resection of metastasis originating from gastric adenocarcinoma. J Gastrointest Surg. 2002;6:682-9.

11. Okano K, Maeba T, Ishimura K, Karasawa Y, Goda F, Wakabayashi H, et al. Hepatic resection for metastatic tumors from gastric cancer. Ann Surg. 2002; 235:86-91.

12. Koga R, Yamamoto J, Ohyama S, Saiura A, Seki M, Seto Y, et al. Liver resection for metastatic gastric cancer: experience with 42 patients including eight long-term survivors. Jpn J Clin Oncol. 2007;37:836-42.

13. Sakamoto Y, Sano T, Shimada K, Esaki M, Saka M, Fukagawa T, et al. Favorable indications for hepatectomy in patients with liver metastasis from gastric cancer. J Surg Oncol. 2007:95:534-9.

14. Cheon SH, Rha SY, Jeung HC, Im CK, Kim SH, Kim HR, et al. Survival benefit of combined curative resection of the stomach (D2 resection) and liver in gastric cancer patients with liver metastases. Ann Oncol. 2008;19:1146-53.

15. Qiu JL, Deng MG, Li W, Zou RH, Li BK, Zheng Y, et al. Hepatic resection for synchronous hepatic metastasis from gastric cancer. Eur J Surg Oncol. 2013; 39:694-700.

16. Marrelli D, Roviello F, De Stefano A, Fotia G, Giliberto C, Garosi L, et al. Risk factors for liver metastases after curative surgical procedures for gastric cancer: a prospective study of 208 patients treated with surgical resection. J Am Coll Surg. 2004;198:51-8.

17. Baek HU, Kim SB, Cho EH, Jin SH, Yu HJ, Lee Jl, et al. Hepatic resection for hepatic metastases from gastric adenocarcinoma. J Gastric Cancer. 2013;13: 86-92.

18. Kono K, Amemiya H, Sekikawa T, lizuka H, Takahashi A, Fujii H, et al. Clinicopathologic features of gastric cancers producing alpha-fetoprotein. Dig Surg. 2002;19:359-65.

19. Li XD, Wu CP, Ji M, Wu J, Lu B, Shi HB, et al. Characteristic analysis of alphafetoprotein-producing gastric carcinoma in China. World J Surg Oncol. 2013; $11: 246$.
20. Inoue M, Sano T, Kuchiba A, Taniguchi H, Fukagawa T, Katai H. Long-term results of gastrectomy for alpha-fetoprotein-producing gastric cancer. $\mathrm{Br}$ J Surg. 2010;97:1056-61.

21. Liu X, Sheng W, Wang Y. An analysis of clinicopathological features and prognosis by comparing hepatoid adenocarcinoma of the stomach with AFP-producing gastric cancer. J Surg Oncol. 2012;106:299-303.

22. Hirajima S, Komatsu S, Ichikawa D, Okamoto K, Shiozaki A, Fujiwara H, et al. Liver metastasis is the only independent prognostic factor in AFP-producing gastric cancer. World J Gastroenterol. 2013;19:6055-61.

23. Gao YB, Zhang DF, Jin XL, Xiao JC. Preliminary study on the clinical and pathological relevance of gastric hepatoid adenocarcinoma. J Dig Dis. 2007; 8:23-8.

24. Baek SK, Han SW, Oh DY, Im SA, Kim TY, Bang YJ. Clinicopathologic characteristics and treatment outcomes of hepatoid adenocarcinoma of the stomach, a rare but unique subtype of gastric cancer. BMC Gastroenterol. 2011;11:56.

25. Ochiai T, Sasako M, Mizuno S, Kinoshita T, Takayama T, Kosuge T, et al. Hepatic resection for metastatic tumours from gastric cancer: analysis of prognostic factors. Br J Surg. 1994;81:1175-8.

26. Miyazaki M, Itoh H, Nakagawa K, Ambiru S, Shimizu H, Togawa A, et al. Hepatic resection of liver metastases from gastric carcinoma. Am J Gastroenterol. 1997:92:490-3.

27. Ambiru S, Miyazaki M, Ito H, Nakagawa K, Shimizu H, Yoshidome H, et al. Benefits and limits of hepatic resection for gastric metastases. Am J Surg. 2001;181:279-83.

28. Shirabe K, Shimada M, Matsumata T, Higashi H, Yakeishi Y, Wakiyama S, et al. Analysis of the prognostic factors for liver metastasis of gastric cancer after hepatic resection: a multi-institutional study of the indications for resection. Hepatogastroenterology. 2003;50:1560-3.

29. Thelen A, Jonas S, Benckert C, Lopez-Hänninen E, Neumann U, Rudolph B, et al. Liver resection for metastatic gastric cancer. Eur J Surg Oncol. 2008;34: 1328-34.

30. Takemura N, Saiura A, Koga R, Arita J, Yoshioka R, Ono Y, et al. Long-term outcomes after surgical resection for gastric cancer liver metastasis: an analysis of 64 macroscopically complete resections. Langenbecks Arch Surg. 2012;397:951-7.

31. Schildberg CW, Croner R, Merkel S, Schellerer V, Müller V, Yedibela S, et al. Outcome of operative therapy of hepatic metastatic stomach carcinoma: a retrospective analysis. World J Surg. 2012;36:872-8.

32. Kinoshita T, Kinoshita T, Saiura A, Esaki M, Sakamoto H, Yamanaka T. Multicentre analysis of long-term outcome after surgical resection for gastric cancer liver metastases. Br J Surg. 2015;102:102-7.

33. Oki E, Tokunaga S, Emi Y, Kusumoto T, Yamamoto M, Fukuzawa K, et al. Surgical treatment of liver metastasis of gastric cancer: a retrospective multicenter cohort study (KSCC1302). Gastric Cancer. 2016;19:968-76.

34. Oguro S, Imamura H, Yoshimoto J, Ishizaki Y, Kawasaki S. Liver metastases from gastric cancer represent systemic disease in comparison with those from colorectal cancer. J Hepatobiliary Pancreat Sci. 2016;23:324-32.

35. Tatsubayashi T, Tanizawa Y, Miki Y, Tokunaga M, Bando E, Kawamura T, et al. Treatment outcomes of hepatectomy for liver metastases of gastric cancer diagnosed using contrast-enhanced magnetic resonance imaging. Gastric Cancer. 2017;20:387-93.

36. Song YX, Huang XZ, Gao P, Sun JX, Chen XW, Yang YC, et al. Clinicopathologic and prognostic value of serum carbohydrate antigen 19-9 in gastric cancer: a meta-analysis. Dis Markers. 2015;2015:549843.

37. Takemura N, Saiura A, Koga R, Yoshioka R, Yamamoto J, Kokudo N. Repeat hepatectomy for recurrent liver metastasis from gastric carcinoma. World J Surg. 2013;37:2664-70.

38. Sun Z, Zheng H, Yu J, Huang W, Li T, Chen $H$, et al. Liver metastases in newly diagnosed gastric cancer: a population-based study from SEER. J Cancer. 2019;10:2991-3005.

\section{Publisher's Note}

Springer Nature remains neutral with regard to jurisdictional claims in published maps and institutional affiliations. 